\section{Evolution Restated}

THE mathematicians and physicists refer things no longer to three axes of co-ordinates, but to four, the fourth being the time axis. The world is 'fourdimensional', and is a world of events. This conception of time as intrinsic to things and not just something that happens to them, is applicable to the biological no less than to the physical sphere, and leads to interesting results, especially as bearing upon the theory of evolution. Some of these corollaries have been indicated by Mr. J. C. MeKerrow in a pamphlet "Evolution without Natural Selection" (London : Longmans, Green and Co., Ltd.) supplementing his "Novius Organum" (1931). The Darwinian theory was that out of a number of chance or random variations a certain number were chosen by 'natural selection' to survive. The difficulty for the Darwinian has always been to account, not for 'natural selection' or survival, but for the occurrence of the variations themselves. But it is obvious that if an organism is a 'four-dimensional process' or a system of activity, an event and not a thing, it is not so much variations as repetition and sameness that call for explanation. In a world of events, things happen, whereas in a world of static fixtures, they do not.

Mr. McKerrow, like Samuel Butler, interprets organic activity (and an organism which as a fourdimensional process is itself an event, that is, activity, not a thing) in terms of habit. Habit accounts for sameness or stability, but it also accounts for variation, because it does not exclude freedom. "All the forces of nature that make for change are just as much available on the assumption of 'habit' as on that of mechanistic causation-with an additional element of 'fortuity' added". On this view, variations are not so much random as "manifestations of the peculiar degree of freedom of living systems". Evolution on this view is positively, not negatively, conditioned. Hypothetical variations are not produced in order to be massacred by natural selection. It is just a case of a four-dimensional Nature display. ing its activity in new happenings. In any event a four-dimensional biology can scarcely leave unchanged our views of the mode of evolution.

\section{Antimony Treatment of Kala-azar}

An article under this title by Sir Leonard Rogers appeared in NATURE of December 16, 1939, p. 1103, which presented in very bare outline the history of the use in India of antimony compounds to combat kala-azar. Sir Upendranath Brahmachari, whose work in connexion with the introduction and use of urea stibamine was referred to briefly, has submitted to NATURE a long statement surveying in some detail the work which led up to the preparation of this substance and reporting on the results obtained. He states that, contrary to Sir Leonard Rogers' statement, urea stibamine was not patented, and claims that divergent results obtained by different investigators were due to the fact that various manufacturers put on the market so-called urea stibamine which did not conform to his specification. Reference is also made to the cost of treatment with antimony compounds. Sir Leonard Rogers stated in his article that a course of treatment with urea stibamine cost $£ 3$ in 1925. In the intervening years, this has happily been reduced; Sir Upendranath states that urea stibamine is now supplied by the Government at Rs. 1 per gram, and since $1.5 \mathrm{gm}$. is sufficient for complete cure, the total cost of the drug to-day is now Rs. 1.8 (about $2 s .3 d$.). This is a reduction on which all who have been concerned are to be congratulated. Yet this cost is still relatively high for a country in which the great majority of the population live dangerously near the starvation line, and there is still room for a rapidly effective and really cheap remedy for kalaazar.

\section{American Archæology and Local Research}

IN view of recent references in NATURE to the stimulation of local interest in archæological research in the United States of America through Federal, National and State funds, it may be of interest to note that the Research Committee of the American Philosophical Society, in awarding grants in the natural and exact sciences from the Penrose Fund in 1938-39, allocated amounts as follows for localized anthropological and archæological investigations. These are additional to continuing grants for researches to which reference is made in another column of this issue of Nature (see p. 558). To Emil W. Hanry, of the University of Arizona, for the excavation of a prehistoric village on Forestdale Creek, Fort Apache Indian Reservation, Arizona, an area of direct contact between the Mogollon and Anasazi cultures, 500 dollars ; Margaret Lantis, University of California, for an ethnographical study of the complete seasonal round of the year of Alaskan Eskimo, 950 dollars ; and Louis W. Chappell, West Virginia University, for the collection and preservation of folk-lore in West Virginia, 500 dollars. The last-named research should prove of special interest in view of its bearing upon cultural exchange between the three strains of white, Indian and Negro. The Indian in the past has suffered in both directions of over-idealization and undue depreciation arising from culture clash. The scientific study of Indian cultures by ethnographical and archæological methods is rapidly widening appreciation in truer perspective.

\section{History of Artificial Eyes}

THE January issue of the Annals of Medical History contains an interesting account, accompanied by numerous illustrations, of the ancient origins of artificial eyes by Dr. Gordon M. Bruce, of New York. The earliest artificial eyes about which there is definite information were made in Egypt for the adornment of mummies, mummy masks and statues, of which many varieties are to be seen in museums. Artificial eyes have also been found in Aztec and Inca mummies, as well as in mummified specimens from Darnley Island in the Torres Strait and the Solomon Islands. The ancient Syrians were familiar with the use of artificial eyes, as is shown by a specimen in the Metropolitan Museum of New York. The existence 